\title{
Capillary Pressure Driven Water Movement in Wet Unsaturated Porous Media: Effect of Particle Electric Charge
}

\author{
Rosa M. Torres Sánchez* \\ Centro de Technología de Recursos Minerales y Ceramíca, CETMIC, \\ Camino Parque Centenario y 506, CC 49, 1897 M. Gonnet, Argentina
}

\begin{abstract}
Experimentos do fluxo da água usando um meio poroso não saturado compoto por diferentes sistemas de $\alpha$ - alumina molhada não-saturada indicam que a carga superficial da partícula diminuiu com o aumento da água movimentada. O movimento máximo de água ocorreu quando a carga superficial era zero. O movimento da água foi afetado pela espessura da dupla camada elétrica no $\mathrm{pH}$ em que as partículas têm carga líquida (a partir do $\mathrm{IEP}_{\mathrm{pH}}$ ). Estes resultados sugerem estruturação da água, induzida por carga, adjacente a superfícies de partículas carregadas.
\end{abstract}

Experiments of water flow using a non saturated porous medium constituted by different $\alpha$ - wet unsaturated alumina systems indicate that particle surface charge decreased the amount of water moved. Maximum water movement occurred when surface charge was zero. Water movement was affected by thickness of the electrical double layer at $\mathrm{pH}$ where particles have net charge (out of the $\mathrm{IEP}_{\mathrm{pH}}$ ). These results suggest charge-induced structuring of water adjacent to charged particle surfaces.

Keywords: alumina, electrical double layer, surface charge, water flow

\section{Introduction}

Prior studies in our laboratories, ${ }^{1-2}$ in agreement with those accomplished by Karkare et $a l .{ }^{3}$ have shown that application of insoluble surfactants to part of a wet unsaturated porous medium leads to water movement from the surfactant-containing to the surfactant-free part of the system. Different surfactants were analyzed on wet unsaturated porous medium (mainly of sand columns). Karkare et $a l .{ }^{3}$ analyzed the effects of 33 different surfactants (long chain alcohols, acids, esters, and amines) on unsaturated flow indicating that effective surfactants must be water insoluble. Notwithstanding, further studies performed by Henry et al. ${ }^{4}$ found that the resultant moisture content distribution in the column was different when the low-solubility alcohol as butanol was used. In the literature, sand was almost always used to simulate the wet unsaturated porous medium, ${ }^{1,5-10}$ and similar results indicate that the surfactant causes differences in capillary pressure within the system and water moves to re-establish equilibrium. ${ }^{7-8}$ The amount of water that moves depends ${ }^{7}$ on all the factors that influence capillary pressure - particle

*e-mail: rosats@cetmic.unlp.edu.ar, rosa.torres@gmail.com wettability, size, size distribution, packing, etc., as well as the character of the surfactant monolayer that establishes the capillary pressure gradient within the system.

In this work the influence of another variable - particle surface charge - on capillary pressure driven water movement in different $\alpha$ - wet unsaturated alumina porous media was examined. The knowledge of the interactions between surfactants and fine particles will help to improve techniques such as soil surfactant-based remediation which is limited by soil texture. ${ }^{11-12}$ A Knowledge that, among others, will help to understand the washing efficiency decrease of surfactants found in soils with large content of fine-sized textural particles (silt, clay and $\mathrm{Fe}$ or $\mathrm{Al}$ oxides). ${ }^{13}$ An extra bonus could also be achieved by the knowledge of charge effects on these interactions in order to be applied on salt solutions nanofiltration through alumina membranes in environmental process, ${ }^{14}$ and to use their attractive properties in membrane filtration systems of $\mathrm{Al}$ oxides, $\mathrm{Al}$ nanoparticles, or heated aluminum oxide particles. ${ }^{15}$ The outlined hypothesis is that if particle surface charge causes orientation of nearby water molecules, there could be a correlation between the particle surface charge and capillary pressure driven movement of water. Minimum hindrance to water movement should occur when particle surface charge is zero. 
The effects of particle surface charge on nearby water have been investigated, with conflicting results. For example, Bijsterbosch and Lyklema ${ }^{16}$ studied alcohol adsorption on silver iodide, concluding that "minimum orientation of water dipoles with respect to the surface depends on the surface charge of silver iodide. The S shape of the alcohol adsorption isotherms can be explained by the assumption of the existence of some structure in the aqueous layer adjacent to the surface. This structure must be broken down before adsorption can occur." They found maximum adsorption of alcohol when the (silver iodide) particles carried a surface charge of about $-1 \mu \mathrm{C} \mathrm{cm}^{-2}$ which they took to be the condition where minimum orientation of water dipoles occurs. In a previous work, ${ }^{17}$ it was reported that the permeability coefficient of water through various colloidal pastes reaches a maximum when charge on the particles is zero and that if other factors are normalized; filtration efficiency can be used as a means of determining the $\mathrm{pH}$ where zero charge is achieved. Tschapek et al. ${ }^{18}$ in 1987 reported that particle surface charge influenced surfactant-driven water movement through wet unsaturated $\alpha$-alumina. However, they found no correspondence of maximum water movement with zero surface charge. In 1991 these same authors, ${ }^{19}$ reported that particle surface charge had no influence on capillary pressure driven water movement through wet unsaturated sand and alumina. Karkare et al. ${ }^{3}$ in 1993, confirmed this negative result for wet unsaturated sand.

Particularly, alumina oxides surface are positively charged over a wide $\mathrm{pH}$ range (from 1.5 to 7.5 ), ${ }^{20}$ but particle surface charge varies with the $\mathrm{pH}$ of the system. The $\mathrm{pH}$ where the electrokinetic potential of a particle is zero is called the isoelectric point (IEP). The $\mathrm{pH}$ where the titratable surface charge is zero is called the point of zero charge (PZC). These two quantities have the same $\mathrm{pH}$ value only in the absence of specific adsorption (adsorption for which the adsorption energy differs from the Coulombic energy). ${ }^{21}$ Specific ionic adsorption shifts both the IEP and the PZC in opposite directions of $\mathrm{pH}$ referred to the charge-determining ions $\left(\mathrm{H}^{+}\right.$or $\left.\mathrm{OH}^{-}\right) .{ }^{22}$ Such a shift explains why Tschapek et al. ${ }^{18}$ in 1987 did not find maximum water movement in wet unsaturated $\alpha$-alumina at $\mathrm{pH} 9.0$, with an indicated PZC of pure alumina determined by titration of $\mathrm{pH} 9 .^{23-24} \mathrm{It}$ is shown below that the $\alpha$-alumina used by Tschapek et al. ${ }^{18}$ is coated with a small quantity of specifically adsorbed material, which makes its isoelectric point $\mathrm{pH} 5.0$ instead of $\mathrm{pH}$ 9.0. Specific adsorption was not recognized by Tschapek et al. ${ }^{18}$, who did find maximum water movement in the vicinity of $\mathrm{pH}$ 5.0.

Depending on the particle surfaces involved, different times are needed to attain suspension equilibrium $\mathrm{pH}$. The initial suspension $\mathrm{pH}$ value may change with time because of solvent reaction with functional groups on the colloidal surface and so may not reflect the $\mathrm{pH}$ of the solid surface when equilibrium between the solvent and the colloidal surfaces is achieved. In the work reported here, suspension $\mathrm{pH}$ was checked repeatedly until equilibrium was achieved.

Particle surface charge should have maximum influence on water that is very close to the particle surface. Closeness is promoted by systems of small particles. Small particles have larger surfaces area to be close to than large particles do. Besides, the spaces between particles in assemblies of small particles are smaller than the spaces between particles in assemblies of large particles. In this work, water movement as a function of surface charge is reported for three different colloids of $\alpha$-alumina whose specific surface areas vary from about 2 to $110 \mathrm{~m}^{2} \mathrm{~g}^{-1}$. These specific surface areas are much higher than the $0.013 \mathrm{~m}^{2} \mathrm{~g}^{-1}$ found for the sand investigated previously,,${ }^{9,25}$ where particle surface charge had no measurable effect on water movement.

\section{Experimental}

\section{Materials}

The colloids studied were $\alpha$-alumina of three different origins (Active Acidic -Activity 1- for Column Chromatography from EM Science, Gibbstown NJ and Alcan and Alcoa, Brazil). The alumina from EM Science was the same colloid, though designated differently, as studied by Tschapek in 1987. The colloids were coded samples A, B and C, respectively. The surfactant was $97 \%$ 1-tetradecanol (Fluka AG, Buchs, Switzerland).

\section{Methods}

Charge densities of the samples were modified by addition of $\mathrm{HCl}$ or $\mathrm{KOH}$ to concentrated colloids slurries. This procedure was repeated until the desired $\mathrm{pH}$ was achieved and this $\mathrm{pH}$ did not change with time (a week). The samples were then dried at $100^{\circ} \mathrm{C}$ overnight. A portion of each dried sample was reintroduced into a proportional amount of water and the $\mathrm{pH}$ was measured again. This final $\mathrm{pH}$ was considered the equilibrium $\mathrm{pH}$ value for each sample.

The procedure for setting up and following a water movement experiment was as previously described. ${ }^{3}$ Figure 1 shows the setup utilized.

The middle $10 \mathrm{~cm}$ sections of $2.54 \mathrm{~cm}$ diameter, $20 \mathrm{~cm}$ long acrylic tubes were packed with wet but unsaturated samples of known initial water content. The left halves of the tubes also contained $(0.02 \mathrm{~g})$ 1-tetradecanol, a quantity 


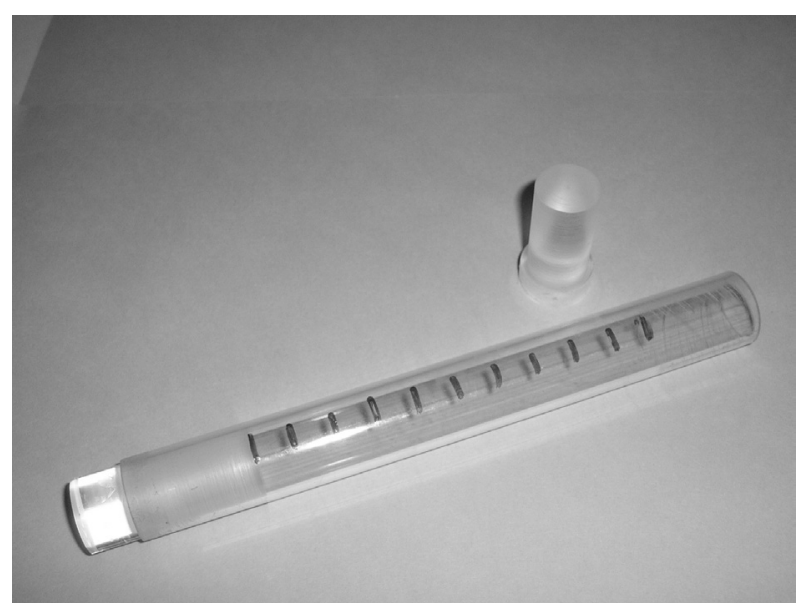

Figure 1. Experimental set up for measuring the water movement.

in excess of the amount required to form close-packed monolayers at the air-water interface within the tubes. ${ }^{7}$ The tetradecanol was mixed with the wet samples. The ends of the tubes were capped and the tubes were placed horizontally. After $24 \mathrm{~h}$, the water contents of different sections along the length of each tube were determined by measuring weight loss on drying and are reported as weight percentages based on weight of the dry sample. Preliminary experiments were made with different initial water contents to find the water content that led to maximum movement of water, ${ }^{7}$ at natural colloid $\mathrm{pH}$. This same water content was used in subsequent experiments with samples whose charge densities had been modified. With the exception of experiments with $\mathrm{KCl}$ solutions that are described below, distilled water was used in all water movement experiments. Equilibrium pH's for samples whose charge densities had been modified were not significantly affected by the water movement experiment. All data were collected at room temperature of approximately $23{ }^{\circ} \mathrm{C}$.

Particle specific surface areas were determined by nitrogen adsorption using BET method, at $-196{ }^{\circ} \mathrm{C}$ in a Quanta Chrome Autosorb instrument (Quanta Chrome, Boynton Beach, FL). Particle size distributions were determined in wet sodium hexametaphosphate with a Model 500 Sedigraph (Micromeritics Corp., Norcross, GA). X-ray diffraction (XRD) analysis was carried out at $40 \mathrm{kV}$ and $20 \mathrm{~mA}$ with $\mathrm{Cu} \mathrm{K}_{\alpha}$ radiation and Ni filter using a Philips Model 3170 instrument (Philips Electronics Company, Mahwah, NJ). Morphology of the particles was observed with a Philips Model 505 scanning electron microscope. Apparent densities of the samples in packed beds were determined by adding dry samples to $10 \mathrm{~mL}$ volumetric flasks. The flasks were tapped and more sample was added until the flasks were filled to the calibration marks and no additional settling occurred. Sample masses were then divided by flask volumes. These measurements were made in triplicate. Average apparent densities are reported.

To identify impurities associated to sample $\mathrm{A}(\alpha$-alumina, EM), a portion of this sample was extracted several times with methanol, at $50^{\circ} \mathrm{C}$. The methanol was evaporated from the extract. The remaining material was coded $\mathrm{A}_{\mathrm{MeOH}}$ and characterized by XRD and FT-IR spectroscopy.

Isoelectric point (IEP) determinations were performed through measurements of diffusion and zeta potentials.

Diffusion potential was determined through two calomel electrodes (Metrohm manufacture) inserted in cells containing $10^{-3}$ and $510^{-3} \mathrm{~mol} \mathrm{~L}^{-1} \mathrm{KCl}$, respectively, where the sample equilibrated at different $\mathrm{pH}$ acts of membrane between the electrolytes of both cells. The EMF measurements were carried out with a digital Electrometer (Keithley Instrument Inc. model 616) with input resistance $>2 \times 10^{14} \mathrm{ohms}$. The transference number $\left(\mathrm{t}^{+}\right)$values were obtained from the EMF's measurements from each sample at the equilibrated $\mathrm{pH} .{ }^{25-27}$ The IEP's were obtained from the $\mathrm{t}^{+} v s$. $\mathrm{pH}$ curves, when $\mathrm{t}^{+}$equals 0.5 . The $\mathrm{t}^{+}$values derive from all the cations that are contained in the sample. However since the quantity of free cations is one hundred times less than the quantity of adsorbed cations, the calculated $t^{+}$is considered, ${ }^{25}$ to correspond to the adsorbed counter ions only.

The zeta potentials were determined by microelectrophoresis (Brookhaven), using $10^{-3} \mathrm{~mol} \mathrm{~L}^{-1} \mathrm{KCl}$ as inert electrolyte.

\section{Results and Discussion}

\section{Samples Characterization}

Especially because of the varying results obtained from previous studies of charge effects on water movement, it was important to make a thorough characterization of the samples studied here.

The particle sizes and surface areas of the samples are given in Table 1. Particularly, surface area value of sample A agrees with the value indicated elsewhere. ${ }^{28}$ Notwithstanding, a low correlation of particle size supplied by the manufacturer with specific surface area obtained in this work is observed, and it is caused by particle agglomeration, as discussed below.

Table 1. Particle size and specific surface area of the samples

\begin{tabular}{lcc}
\hline Sample & $\begin{array}{c}\text { Surface area } \\
\left(\mathrm{m}^{2} \mathrm{~g}^{-1}\right)\end{array}$ & $\begin{array}{c}\text { Particle size } \\
\left(\mathrm{d}_{50}, \mu \mathrm{m}\right)\end{array}$ \\
\hline A $(\alpha-\mathrm{A} 12 \mathrm{O} 3$, EM Science $)$ & 109.9 & $63-200^{*}$ \\
B ( $\alpha$-A12O3, Alcan $)$ & 2.0 & 4.0 \\
C $(\alpha-\mathrm{A} 12 \mathrm{O} 3$, Alcoa $)$ & 10.2 & 0.5 \\
\hline
\end{tabular}




\section{Electron micrographs of the samples are shown in Figure 2}

The micrograph of Sample A, Figure 2A, shows agglomeration of these $\alpha$-alumina particles. This agglomeration can explain the inconsistent correlation of surface area with particle size for this sample. Hand
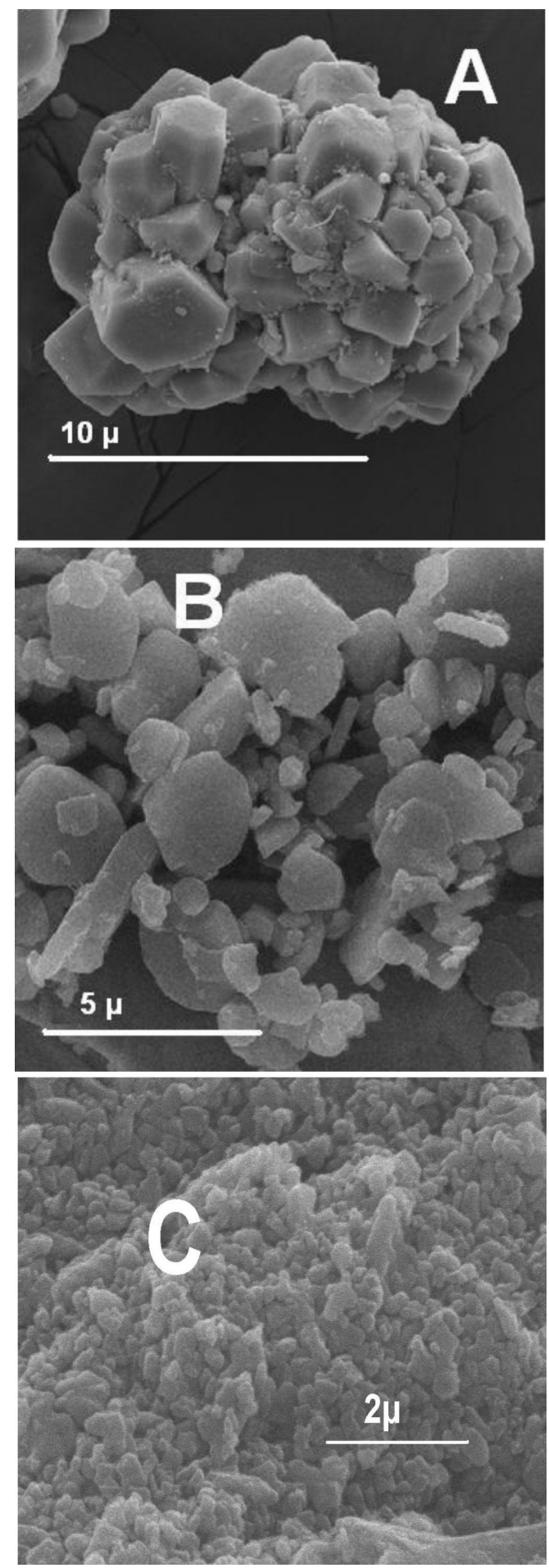

Figure 2. Electron microphotograph of the samples: A, $\alpha$-Alumina (EM); $\mathrm{B}, \alpha$-Alumina (Alcan) and C, $\alpha$-Alumina (Alcoa). grinding with an agate mortar destroys the agglomerates, as was shown by electron microscopy (figure not shown). $\mathrm{The} \mathrm{NaCl}$ and $\mathrm{KCl}$ and the amine observed by XRD and FT-IR, respectively, may serve as binders to agglomerate the alumina particles. The micrographs of Samples B and C evidence differences, mainly, in the particle size.

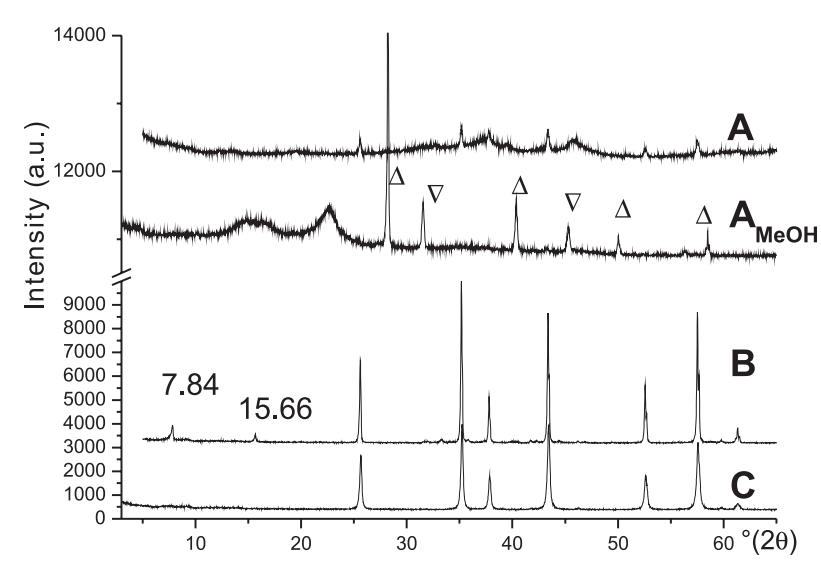

Figure 3. X-ray diffraction patterns of samples $\mathrm{A}, \mathrm{A}_{\mathrm{MeOH}}, \mathrm{B}$, and $\mathrm{C}($ identifies peaks for $\mathrm{KCl}$ and $(\nabla)$ identifies peaks for $\mathrm{NaCl}$.

X-ray diffraction patterns for the samples, and the material extracted from the $\alpha$-alumina (EM), are shown in Figure 3. The sample A showed the characteristic peaks of a poorly crystallized $\alpha$-alumina, ${ }^{29}$ as well as peaks at 31.53 and $45.28^{\circ}(2 \theta)$ assigned to $\mathrm{NaCl}$. The $\mathrm{X}$-ray patterns for the $\mathrm{A}_{\text {meoH }}$ sample showed peaks at $28.20,40.37,50.04$, and $58.65^{\circ}(2 \theta)$ and $31.53,45.28$ and $58.49^{\circ}(2 \theta)$ corresponding to $\mathrm{KCl}$ and $\mathrm{NaCl}$, respectively and enlarged peaks around $13-17$ and $22-23^{\circ}(2 \theta)$ could correspond to an aliphatic amine (e.g. methylbutyramine). Identification by X-ray diffraction was not possible due to the overlapping of peaks of the detected salts. However, infrared spectroscopy of the $\mathrm{A}_{\mathrm{MeOH}}$ sample (figure not shown) showed absorption bands at $1406.8,1663.9,2856.8$ and $2923.8 \mathrm{~cm}^{-1}$ which allowed the sample to be identified as an aliphatic amine. ${ }^{30}$ Samples $\mathrm{B}$ and $\mathrm{C}$ show the characteristic peaks of crystallized $\alpha$-alumina. Particularly peaks at 11.25 and $5.64 \AA$ (7.84 and $\left.15.66^{\circ}(2 \theta)\right)$ in B sample indicate the presence of $\beta$-alumina.

\section{Determination of Isoelectric Points and Points of Zero Charge}

Table 2 resume the IEP values determined from diffusion potential after measurements of transference numbers $\left(\mathrm{t}^{+}\right)$ and PZC obtained by zeta potential measurements for all the samples. The IEP values for the B sample, $\mathrm{pH} 10.7$, agree with literature values for $\alpha$-alumina. ${ }^{23-24,31}$ The IEP found for the samples A and C, pH 5.2 and 9.3 are lower than the $\mathrm{pH} 10.5$ indicated in the literature for $\alpha$-alumina. ${ }^{23-24,31}$ 
This difference, particularly, in sample $\mathrm{C}$ can be explained by the presence of iron as impurity $(0.06 \%$ determined by chemical analysis) and evidenced by the appearance of red color after a thermal treatment at $500{ }^{\circ} \mathrm{C}$ and/or the presence of $\beta$-alumina observed by $\operatorname{XRD}^{32}(8.5 \% \mathrm{~m} / \mathrm{m}$ of diaoyudaoite $\mathrm{NaAl}_{11} \mathrm{O}_{17}$ determined by XRD using Rietveld method). ${ }^{33}$ The low $\mathrm{IEP}_{\mathrm{pH}}$ obtained for sample A suggests an anionic coating on the alumina, perhaps placed there to make a better column for chromatographic use. To confirm that the amine coating on this sample changed the IEP, zeta potential of the A sample was carried out to determine the PZC. A PZC value of $\mathrm{pH} 9.5$ was obtained which is very different from the IEP value of $\mathrm{pH}$ 5.2. As was indicated previously, the coincidence and difference of PZC and IEP values indicated the absence and presence of coating, respectively.

Table 2. IEP values determined from diffusion potential alfer measurements of transference numbers $(\mathrm{t}+)$ and PZC obtained by zeta potential measurements for all samples

\begin{tabular}{lcc}
\hline Sample & $\begin{array}{c}\text { IEP } \\
(\mathrm{pH})\end{array}$ & $\begin{array}{c}\text { PZC } \\
(\mathrm{pH})\end{array}$ \\
\hline A $(\alpha-\mathrm{Al} 2 \mathrm{O} 3$, EM Science $)$ & 5.2 & 9.5 \\
$\mathrm{~B}(\alpha-\mathrm{Al} 2 \mathrm{O} 3$, Alcan $)$ & 10.7 & 10.5 \\
$\mathrm{C}(\alpha-\mathrm{Al} 2 \mathrm{O} 3$, Alcoa $)$ & 9.3 & 9.2 \\
\hline
\end{tabular}

\section{Determination of Water Movement}

The amount of water moved by surfactants in wet unsaturated porous media varies with the initial saturation of the media and differs among systems. For a given system, it depends on the relationship between capillary pressure and water content and on the hysteresis of the surfactant desorption - water sorption curves. ${ }^{4}$ The dependence of water moved percentage (mass of water lost from the left side of the column divided by the total mass of dry sample in the column times 100) on initial water percentage (initial mass of water in the column divided by mass of the dry sample in the column times 100) at natural $\mathrm{pH}$ for the samples used in this work is shown in Figure 4. Polynomial curves were used to connect all points only as a guide for the eye, the regression coefficient $\left(\mathrm{R}^{2}\right)$ found in all cases were $>0.9$. Maximum $\%$ water movement occurred at 52 , 28 and $26 \%$ initial water for the samples A ( $\alpha$-alumina EM), B ( $\alpha$-alumina from Alcan) and C ( $\alpha$-alumina from Alcoa). The maximum $\%$ water moved was approximately $1 \%$ for samples B and C and $12 \%$ for sample A. These numbers scale to the specific surface areas of these samples listed in Table 1. Maximum \% water moved for A sample agrees with results found for sand, ${ }^{3}$ indicating the high influence in these value of the particle size of the sample.

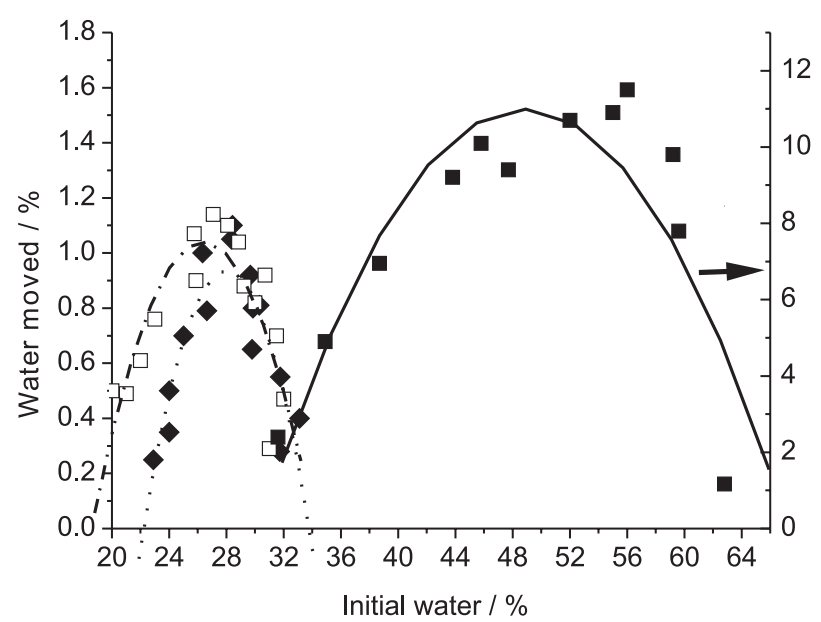

Figure 4. Dependence of $\%$ water moved on initial $\%$ water at natural $\mathrm{pH}$ for $\alpha$-alumina $(\square)$ EM, $(\square)$ Alcan and $(\diamond)$ Alcoa samples. Open symbols follows the right axes, and closed the left one.

Capillary pressure-water content data for these systems are not available.

\section{Effect of surface charge}

The effect of surface charge on water movement was studied at the $\%$ initial water where the largest $\%$ water movement occurred (obtained form Figure 4). Graphs of $\%$ water moved $v s$. system $\mathrm{pH}$ for all the samples are shown in Figure 5. Polynomial curve for sample $B$ have $a R^{2}=0.83$, for all other samples the $\mathrm{R}^{2}>0.9$. In all cases, maximum water movement occurred close to the $\mathrm{pH}$ of the isoelectric point indicated by the arrow.

\section{Effects of neutral electrolyte}

To take into account other factors apart from those that might influence water movement differently at different pH's (surface charge) and those that should affect packing surface charge (changes in electrical charge on the particles), apparent densities and sediment volumes for the A sample was determined at different pH's. Apparent densities and calculated sample void fractions are shown in Table 3. The small changes in apparent densities and void fractions were not judged large enough to cause the differences in $\%$ water moved that have been noted. There

Table 3. Apparent densitie $4 \mathrm{~s}$ and calculated Void fractions at indicated $\mathrm{pH}$

\begin{tabular}{lccc}
\hline Sample & $\mathrm{pH}$ & $\begin{array}{c}\text { Apparent } \\
\text { density } \\
\left(\mathrm{g} \mathrm{cc}^{-1}\right)\end{array}$ & $\begin{array}{c}\text { Calculated } \\
\text { Void } \\
\text { fractions }\end{array}$ \\
\hline & 5.5 & 1.07 & 0.731 \\
$\mathrm{~A}(\alpha-\mathrm{A} 12 \mathrm{O} 3$, EM Science) & 4.4 & 1.24 & 0.687 \\
& 3.7 & 1.12 & 0.718 \\
\hline
\end{tabular}



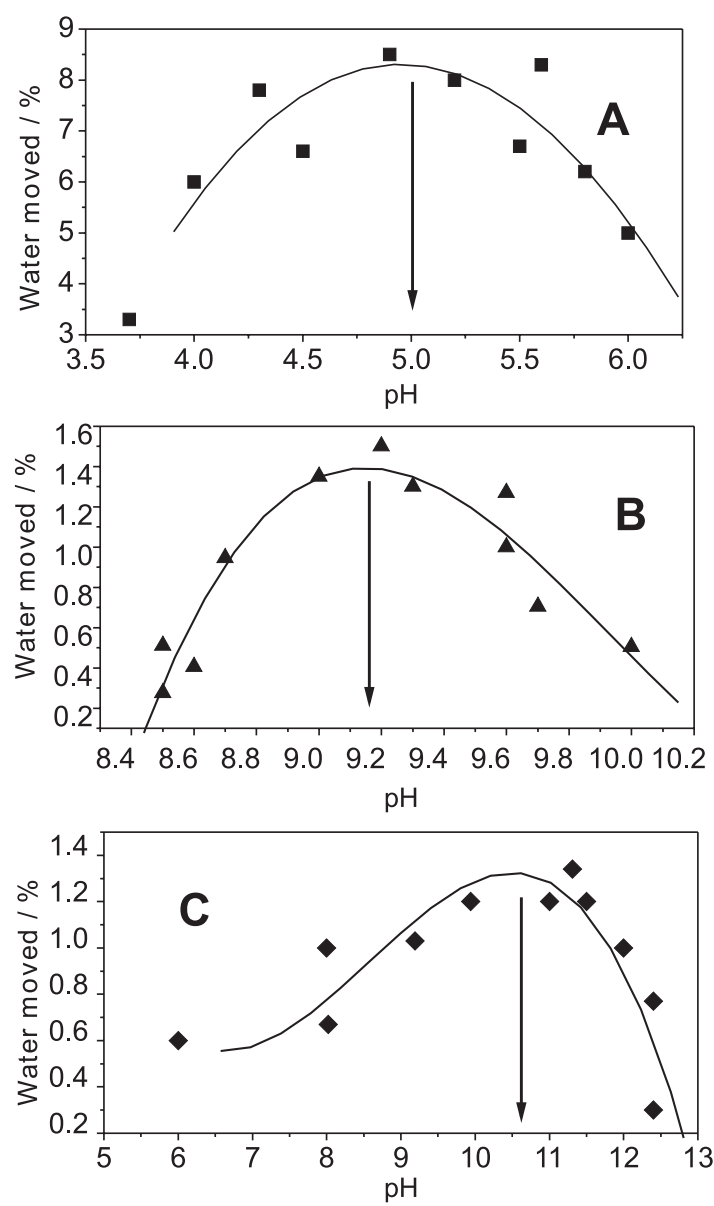

Figure 5. Dependence of water movement on $\mathrm{pH}$ for A-alumina (EM), B-alumina (Alcan) and C-alumina (Alcoa), at initial water content of 43, $42,60,30$ and $28 \%$, respectively.

was no correspondence of water movement with very minimal changes in sediment volumes, results not shown.

Experiments were performed to determine the effect of a neutral electrolyte $(\mathrm{KCl})$, on capillary pressure driven water movement in wet unsaturated $\alpha$-alumina (EM and Alcoa), at $\mathrm{pH}$ where the particles are electrically neutral (around the $\mathrm{IEP}_{\mathrm{pH}}$ ) and charged positively $(\mathrm{pH} 3.8$ and 8.2 for samples A and C, respectively). Results are shown in Figure 6 A and B for samples A and C, respectively. Regression coefficients were higher than 0.87 for all curves. The open symbols indicate water movement when the "wet" medium was distilled water. The closed symbols indicate water movement when the "wet" medium was an aqueous solution with $\mathrm{KCl}$. There was no significant difference in results obtained for $\mathrm{pH} 5.0$ and 9.4 close to that of the IEP for both samples (5.2 and 9.3, for samples $\mathrm{A}$ and $\mathrm{C}$, respectively). The compression of the electrical double layer was not evidenced in the $\mathrm{IEP}_{\mathrm{pH}}$ where the particles are electrically neutral nor for the positively charged relatively larger particles of the A sample. When the samples were positively charged $(\mathrm{pH} 3.8$ and
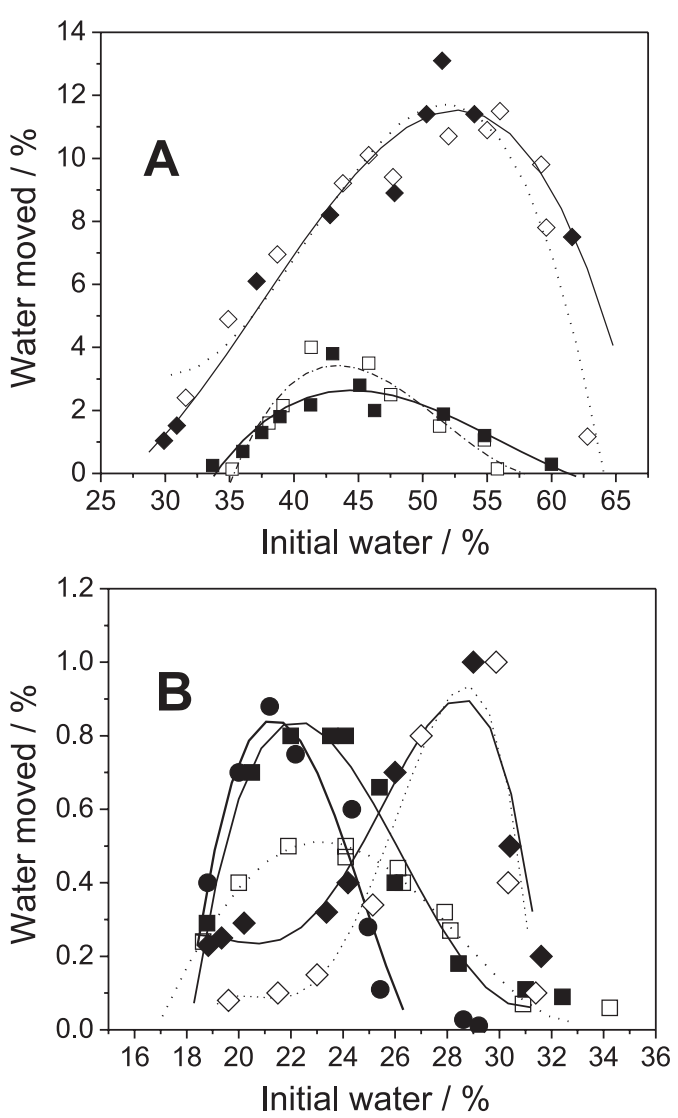

Figure 6. Effect of a neutral electrolyte $(\mathrm{KCl})$ on capillary pressure driven water movement in wet unsaturated $\alpha$-alumina. Open symbols (M,') indicate water and closed symbols $(\bullet, \square) 0.1$ and (,) $1 \mathrm{~mol} \mathrm{~L}^{-1} \mathrm{KCl}$. (A) Sample A: rhombus and squares symbols indicate $\mathrm{pH} 5.0$ and $\mathrm{pH} 3.8$, respectively and (B) Sample C: rhombus symbols indicate $\mathrm{pH} 9.4$ and squares and round symbols indicate $\mathrm{pH} 8$.

8.2 for samples $\mathrm{A}$ and $\mathrm{C}$ ) the maximum $\%$ initial water shifted to a lower value (from $52 \%$ to $45 \%$ and from 29 to around $22 \%$, for samples A and C, respectively) with an increase in the maximum \% water moved as shown in Figure 6 (for a fixed $\%$ initial water). With the small and positively charged particles of the sample $\mathrm{C} \%$ water moved increased up to the value found for same sample neutrally charged.

\section{Conclusions}

The experiments showed a relationship between particle surface charge and capillary pressure driven water movement. Water movement is a maximum at the $\mathrm{pH}$ corresponding to the isoelectric point of the particles. As $\mathrm{pH}$ of the suspension shifts from the IEP $\mathrm{pH}$, the amount of water moved for a given sample decreases. These results suggest that particle surface charge causes structuring of water molecules that makes them more difficult to move. Electrical double layer thickness appears to affect water movement, mainly in low particle size samples. 


\section{Acknowledgments}

Financial support from ANPCyT-FONCyT for financial support through PICT 1360 project and from the CONICET-NSF Programs through Award 1230/31-800 and 2491/11-12-00 are gratefully acknowledged. The author also thanks, Eng. P. Montardit and M. Dapino and Lic. A. M. Cesio for their help in preparation experiences and XRD pattern identification, respectively.

\section{References}

1. Tschapek, M.; Boggio, L.; Z. Pfla. Boden. 1981, 144, 30.

2. Tschapek, M.; Wasowski, C.; Torres Sánchez, R. M.; Colloids Surf. 1981, 3, 293

3. Karkare, M.; La, H.; Fort, T.; Langmuir 1993, 9, 1684.

4. Henry, E. J.; Smith, J. E.; Warrick, A.; J. Hydrol. 1999, 223,164.

5. Henry, E. J.; Smith, J. E.; Warrick, A.; J. Hydrol. 2001, 245, 73.

6. Henry, E. J.; Smith, J. E.; Langmuir 2003, 19, 4047.

7. Karkare, M.; Fort, T.; Langmuir 1993, 9, 2398.

8. Karkare, M.; Fort, T.; Langmuir 1994, 10, 3701.

9. Karkare, M.; Fort, T.; Langmuir 1996,12, 2041.

10. Silverstein, D. L.; Fort, T.; Langmuir 2000,16, 829.

11. Kuhlman, M. I.; Greenfield, T. M.; J. Hazard. Mater. 1999, 66, 31.

12. Lee, D. H.; Cody, R. D.; Kim, D. J.; Choi, S.; Environ. Int. 2002, 27, 681.

13. Conte, P.; Agretto, A.; Spaccini, R.; Piccolo, A.; Environ Pollut. 2005, 135, 515.

14. Alami-Younssi, S.; Larbot, A.; Persin, M.; Sarrazin, J.; Cot, L.; J. Membr. Sci. 1995, 102, 123.

15. Maximous, N.; Nakhla, G.; Wan, W.; Wong, K.; J. Membr. Sci. 2009, 341, 67.

16. Bijsterbosch, B. H.; Lyklema, J. In Structural properties of the silver iodide-aqueous solution interfaces; Fowkes, F., ed.; Academic Press: 1969, pp.164.
17. Torres Sánchez, R. M.; Mater. Chem. Phys. 1990, 26, 173.

18. Tschapek, M.; Wasowski, C.; Falasca, S.; J. Dispersion Sci. Technol. 1987, 8, 493.

19. Tschapek, M.; Wasowski, C.; Falasca, S.; Colloids Surf. 1991, $55,1$.

20. Karimi, M. A.; Behjatmanesh-Ardakani, R.; Goudi, A. A.; Zali S.; J. Braz. Chem. Soc., 2008, 19, 1523.

21. Breeuwsma, A.; Lyklema, J.; J. Colloids Interface Sci. 1973, $4,437$.

22. Lyklema, J.; Fundamentals of Interface and Colloid Science: Solid-Liquid Interfaces; Lyklema, J., ed.; Academic Press: London, 1995.

23. Parks, G.; Chem. Rev. 1965, 65, 177.

24. Tschapek, M.; Torres Sánchez, R. M.; Wasowski, C.; Anales Edaf. Agrobiol. 1979, 38, 3.

25. Natale, I.; Tschapek, M.; Geoderma 1970, 4, 73.

26. Torres Sánchez, R. M.; Gasalla, H. J.; Pereira, E.; React. Solids 1989, 7, 53.

27. Torres Sánchez, R. M.; Mater. Sci. Lett. 1996, 15, 461.

28. Ramos, A. R.; Arguello, J.; Magosso, H. A.; Gushikem, Y.; J. Braz. Chem. Soc. 2008, 19, 4, 755 .

29. Bahlawane, N.; Watanabe, T.; J. Am. Ceram. Soc. 2000, 83, 2324.

30. Silverstein, R. M.; Webster, F. X.; Spectrometric identification of organic compounds, $6^{\text {th }}$ ed., John Wiley: New York, 1998.

31. Torres Sánchez, R. M.; Boix, A.; Mercader, R.; J. Mater Res. 2002, 17, 712 .

32. Gitzen, G. In Alumina as a ceramic material; Gitzen, G., ed.; Wiley-American Ceramic Society: Columbus Ohio, 1970, ch. 3.

33. Pascoal, C.; Maçado, R.; Pandeolfelli, V.; 43 . Congresso Brasileiro de Cerâmica, Florianópolis, Brasil, 1999.

Received: May 5, 2009

Web Release Date: November 26, 2009 